\title{
Yo $\mathfrak{x} \mathfrak{w} \circ \mathfrak{n} \mathfrak{t}$.
}

Dură die (Einführung dę neuen Bürgerliđen BSe=

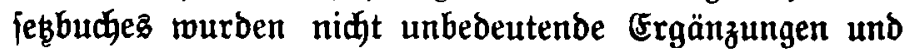

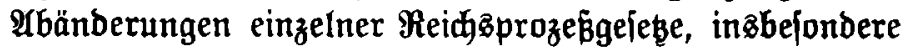

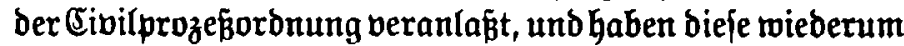

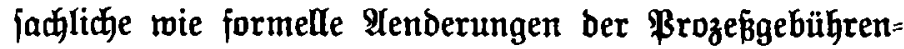
gejetze, wie fie in ber Faijung ber Befanntmađung bes

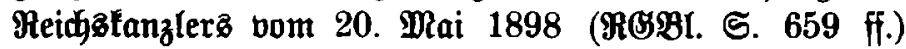
mitgetbeilt wurben, zur nothwendigen Folge gehabt.

3roet bez vorliegenden Seandbudjez ift nun, alle für ben Sivil=, Sonfurz= ober Strafprozeß in Betradt

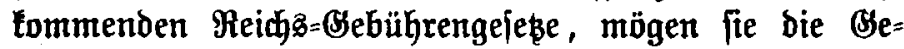
bührenerhebung nur für bie Staatżłaffe ober aud bie für bie Thätigfeit von Beamten ober anberen ßerjonen betreffen, zu einem abgeidfofienen Ganzen zu vereinen und jo bie Qǚfe zroijhen ben reinen Textauggaben und ben Rommentaren bem Bedürinifie entiprectjend aus= zufüllen.

In bemielben ift nad) Sidftung bes reidylid) zur Berfügung itehenden $\mathfrak{A}$ uslegungżmaterials bie vorherr =

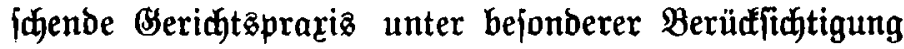

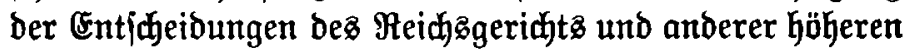

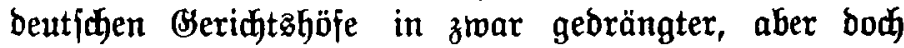
möglidjit vollitänoiger Darftellung niebergelegt. Das Bud foll im 3ujammentalte mit ben nöthigen Be= bührentabellen jowohl dem Braftifer, welder fïh mit ber hier behambelten Materie befafjen musi, als aud 
Demienigen, weldher fid in ber Bebührengejeggebung

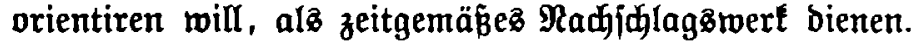

Peöge ę fĭd daher als ein nüblidger und braud)= barer Führer erweijen, und möge bie Mühe, bie ber Unterzeidgnete biejer jeiner zmeiten $\mathscr{A r b e i t}$ auf bem $\mathrm{Ge}=$ biete bez (Beridhtzlojtenmejenz gemibmet hat, burd wohl= mollende 9 Aufnahme und Beurtheilung feines Berfez belognt werben.

Eminbergeim, im Februar 1899.

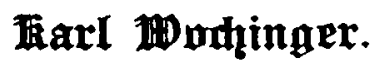

